\title{
THE INFLUENCE OF THE CALIBRATION METRIC ON DESIGN FLOOD ESTIMATION USING CONTINUOUS SIMULATION
}

\author{
PHUONG THI CU ${ }^{(1)}$, JAMES E BALL ${ }^{(2)}$ \\ ${ }^{(1)}$ Doctoral Student, School of Civil and Environmental Engineering, University of Technology Sydney, \\ Broadway, NSW, 2007, AUSTRALIA, E-mail: Thi.P.Cu@student.uts.edu.au \\ ${ }^{(2)}$ School of Civil and Environmental Engineering, University of Technology Sydney, Broadway, NSW, 2007, \\ AUSTRALIA, E-mail: james.ball@uts.edu.au
}

\begin{abstract}
Estimation of design flood flow has been and remains a concern for both hydrologic research and hydrologic practice. Knowledge of design flood flows provides a basis for sustainable flood management, which has the aim of reducing flood risk, thereby protecting people's lives and property. Design floods for a given location can be estimated by a number of approaches including analysis of past flood statistics and the use of catchment modelling. When catchment modelling approaches are applied estimation of design flood flows, there is a need to calibrate the model parameters. As part of this calibration process, a calibration metric, or fitness measure, is needed to enable assessment of alternative sets of parameter values. Presented herein is an investigation into design flood quantiles derived from predictions obtained from a continuous catchment modelling system when alternative calibration metrics are used to assess the suitability of parameter values. Two alternative calibration metrics are considered with one calibration metric aimed at ensuring replication of recorded hydrographs and the second calibration metric aimed at ensuring replication of the statistical characteristics of the Annual Maxima Series. It was found that use of the later calibration metric resulted in better reproduction of the flood probability model estimated from the historical data while reproduction of the recorded hydrographs (i.e. the first calibration metric) did not ensure reproduction of the flood probability model.
\end{abstract}

Keywords: Flood flow, hydrology, flood frequency analysis, continuous simulation.

\section{INTRODUCTION}

Simulation in hydrology refers to the replication of the flows that could have been recorded if a gauge were present at the location of interest. Developments in this approach can be traced from very simple manual calculation systems to the more complex computerised systems currently used. Catchment simulation can be event - based or continuous; for continuous simulation, the flow is simulated during both dry and wet periods. The degree of belief in predictions normally will depend on the success of reproduction of observations. Therefore, the choice of the fitness measure that assesses agreement between simulated and observed data is important. 
Hydrograph based measures of fit have been widely used to assess the modelling fitness in many event - based modelling studies (see, for example, Criss et al. 2008, Gupta et al. 2009, Krause et al. 2005). The hydrograph measures of fit considered have included the Nash-Sutcliff efficiency (NSE), sum of weighted absolute errors; squared residuals; percent error in peak; and peak-weighted root mean square error. The appropriateness of these criteria for measuring goodness of fit, has been debated in the literature (see, for example, Krause et al., 2005, Legates and McCabe, 1999, Seibert, 2001, Smithers, 2012, Gupta et al., 2009). As part of this debate, modified versions of the NSE have been proposed by Garrick et al. (1978), Refsgaard and Knudsen (1996), Legates and McCabe (1999), McMillan and Clark (2009) and Podger (2004). One conclusion that can be deduced from consideration of the literature is that some measures of fit are influenced by particular flow magnitudes (e.g. high or low flows) and hence, the purpose of the modelling needs to be considered in selecting the appropriate measure of fit.

For continuous simulation, hydrograph fitting methods are more challenging due to the sensitivity of different performance measures related to different flow magnitudes (Westerberg et al., 2011). Attempts to address this issue have included a time series approach where the annual maxima series (AMS) (Cameron et al., 1999, Calver and Lamb, 1995) or the flow duration curve (Westerberg et al., 2011) were used as performance measures. From a design flood estimation perspective, Cameron et al. (1999) tested the predicted and recorded AMS using a t-test and selected the parameters that resulted in the best correlation between the predicted and recorded AMS. Implicit in this approach is the assumption that small variations in the AMS do not result in large variations in the flood quantiles: in other words, subtle variations in the AMS do not result in changes to the parameters defining the statistical model of floods.

Ball (2013) reported on estimated design flood quantiles obtained when a hydrograph measure of fit was employed to assess model suitability. Both event-based and continuous simulation approaches were considered. In both these cases, the estimated design flood quantiles were not similar to those estimated from recorded data.

As design flood estimation is concerned with the prediction of flood quantiles, we have investigated how two alternative measures of fit influence these predictions. The two alternative measures of fit considered were the NSE and the parameters of the flood probability model. A monsoon catchment in Vietnam, namely the area of Ba river upstream of the An Khe gauge was used as the test catchment for the investigation. 


\section{DESIGN FLOOD ESTIMATION}

Design flood characteristics must be interpreted from a statistical viewpoint. This contrasts with the analysis of historical flood events where a deterministic viewpoint is appropriate. When design flood characteristics are required, as discussed by Ball (2013), there are two alternative situations which are:

- Sufficient historical information is available for a statistical analysis; and

- Sufficient historical information is not available.

For those situations where there are insufficient data for a statistical analysis, catchment modelling techniques commonly are employed. Catchment modelling techniques may be categorized as event (either complete event or most significant burst) or continuous simulation. The aim of continuous simulation is to estimate flow sequences analogous to those where sufficient historical data are available. Hence, a flood frequency analysis (FFA; see, for example, Kuczera and Franks 2016) of flow data from continuous simulation is needed for design flood estimation; this is similar to of the situation for historically recorded data.

At a site with sufficient measured flood data, the design flood flow can be estimated by a flood frequency analysis (FFA). As reported by Kuczera and Franks (2016), application of FFA requires resolution of:

- Choice of the flood series;

- Errors in the flood series due to the measurement method;

- Selection of a suitable statistical distribution model; and

- Determination of the parameters for that distribution.

\subsection{Choice of Flood Series}

Selection of the most appropriate flow series for flood design estimation has received widespread attention. The two main flood series considered are the AMS and the Peak-over-Threshold Series (POTS). Kuczera and Franks (2016) discussed the relationship between POTS and AMS and recommended the use of an AMS for estimation of low annual exceedance probability events. Using that recommendation, an AMS was preferred for the case study discussed in the later sections.

Included in the choice of a flood series is consideration of the need to censor data and the inclusion of historical flood data. While there are many alternative approaches to identification of data that should be censored, the general concept is one of identifying those data points that depart significantly from the trend of the remaining data. Examples of approaches for identifying data that should be censored are provided by (US Interagency Advisory Committee on Water Data, 1982), Grubbs and Beck 
(1972), and Cohn et al. (2013). Historical data, on the other hand, are events recorded prior to commencement of the monitoring programme. As discussed by Kuczera and Franks (2016), these events may be informative for the defining the parameters of the statistical model fitted to the flood series.

\subsection{Statistical Model}

In the past, many alternative probability distributions have been proposed for defining the statistical characteristics of recorded flood events. When an AMS is used to extract the flood series, Kuczera and Franks (2016) note that two families of distribution have been found to fit flood data; these are the generalized extreme value (GEV) and log Pearson III (LPIII). Furthermore, they note that the choice of an appropriate statistical model for prediction of peak flood flows for a particular site or region can be made only by testing the goodness-of-fit for a statistical model with data for that catchment or region. An LP-III was used for the case study reported in the later sections.

\subsection{Determination of Distribution Parameters}

Probability distribution fitting or simply distribution fitting is the determination of the parameter values for a selected probability distribution using recorded flood data to predict the flood frequency curve. In application of FFA techniques, there are three main techniques used for fitting probability distributions; these techniques are: the Method of Moments, Bayesian techniques and L-moment and LH moment techniques.

The Bayesian approach, as described by Lee (1989), is a general approach to fitting parameters to data. The approach considers a set of data, for example flood flow peaks (D), hypothesized and a random realization from the probability model $\mathrm{M}$, with probability density function $\operatorname{pdf} \mathrm{p}(\mathrm{D} \mid \beta, \mathrm{M})$ where $\beta$ is an unknown finite-dimensioned parameter vector. The term of $p d f p(D \mid \beta, M)$ is dependent on the context. When $p(D \mid \beta, M)$ is used to describe the probability model generating the sample data $\mathrm{D}$ for a given $\beta$, it is called the sampling distribution. However, when inference about the parameter $\beta$ is sought, $p(D \mid \beta, M)$ is called the likelihood function to emphasize that the data $D$ are known and the parameter $\beta$ is the object of attention. In Bayesian inference, the parameter vector $\beta$ is considered a random vector, the probability distribution of which describes the true value of $\beta$. However, the prior pdf $\mathrm{p}(\beta \mid \mathrm{M})$ for given probability model $\mathrm{M}$ known $\beta$ can be used as information to refine $\beta$. Bayes theorem describes the true value of $\beta$ by the following posterior density function (Kuczera and Franks, 2016):

$$
p(\beta \mid D, M)=\frac{p(D \mid \beta, M) p(\beta \mid M)}{p(D \mid M)}
$$


In using this approach, the inputs (observed flood peaks in this case) are treated as a set of data, the true value $\beta$ of which can be described by the density function. The posterior distribution $p(\beta \mid D, M)$ fully defines the parameter uncertainty and is sampled by the "Importance Sampling" method described in Kuczera and Franks (2016). This Bayesian approach has been implemented in FLIKE (Kuczera and Franks, 2016) which was used to analyse the recorded data.

\section{MEASURES OF FIT}

The degree of belief in predictions obtained from a model normally will depend on how well they can reproduce observations; in other words, in comparing the predictions obtained from two models, those predictions obtained from the model that more closely reproduces the recorded data will be considered more reliable than those from the alternative model. Therefore, the choice of the fitness measure that assesses the agreement between simulated and observed data is an important choice in any modelling study. Two alternative measure of fit are considered herein. These alternative measures of fit are hydrograph fitting and time series fitting; details of these metrics are presented in the following sections.

\subsection{Hydrograph measure of fit}

In using a hydrograph measure of fit, the desired outcome is a model that reproduces the shape and other characteristics of the hydrograph. For FFA, the largest peak flow in a year assessed from the predicted hydrographs is then used to develop the AMS.

A commonly used performance measure for a hydrograph fitting application (see, for example, Krause et al., 2005, Legates and McCabe, 1999, Seibert, 2001, Criss and Winston, 2008, Das et al., 2008, Gupta et al., 2009, McMillan and Clark, 2009) is the NSE which can be expressed as:

$$
N S E=1-\frac{\sum_{i=1}^{N}\left(O_{i}-P_{i}\right)^{2}}{\sum_{i=1}^{N}\left(O_{i}-\bar{O}\right)^{2}}
$$

\subsection{Time series measure of fit}

An alternative hydrograph measure of fit is to use a measure more closely related to the desired aims of the modelling. For application of a design flood estimation approach, the aim of using a continuous simulation catchment modelling system is the development of flow records analogous to those that would have been recorded if a gauge were present at that location. From these generated records, the AMS is extracted and then analysed using FFA techniques.

Hence, the desire is for the predictions from the continuous modelling system to result in an AMS that has similar statistical characteristics to the recorded flows. Use of a time series measure of fit, 
therefore, uses the AMS, or the outcomes from analysis of the AMS, as an objective function for calibration and validation of the modelling outcomes.

\section{TEST CATCHMENT}

\subsection{Location}

The Ba River, Vietnam located in South Central Vietnam was chosen as a test catchment for the analysis being presented herein. The Ba River is one of the largest river systems in central Vietnam. The headwaters for the system are found in the Ngoc Ro mountain (Truong Son ridges) in Kon Tum province. The study reported herein used an unregulated $1350 \mathrm{~km}^{2}$ area of the catchment upstream of the An Khe gauge. This portion of the catchment comprises high to moderate mountainous areas, and is located mostly in the eastern part of the Central Highlands of Vietnam (VKT KTTV\&MT 2010).

\subsection{Climate}

The Ba River catchment is located in a tropical monsoon climatic regime. The main features of this climate are extraordinarily rainy wet seasons and pronounced dry seasons. The wet season consists of 5-6 months from May to October or November with about 90\% of the total annual rainfall occurring in this period. The average number of wet days in this season is $22-24$ days/month. Foehn winds and tropical cyclones strongly affect the area during the wet season. A distinct cyclone season occurs later in the summer period from September to December, sharply peaking in October (VKT KTTV\&MT, 2010). During a thunderstorm, the 24-hour rainfall can be as high as $228 \mathrm{~mm}$ (19 November 1987) at Pleiku station.

\subsection{Data availability}

Daily rainfall data are available at 12 stations both within and nearby the catchment (see Figure 1 for locations of these gauges). Rainfall records at almost all of these stations are available for more than 30 years covering the period $1980-2011$. However, there are only four rainfall stations recording hourly rainfall with periods of record ranging from 14 to 33 years (from 1976 to 2011).

Flow data are observed at An Khe station. These data are available in hourly and 6-hourly intervals from 1980 to 2011.

\section{DESIGN FLOOD FLOW}

Design flood flows at the An Khe station were estimated from the historical data using FFA. Application of a flood frequency method requires consideration of:

- Selection of flood series and censoring of the data; 
- Selection of distribution function and estimation of its parameters; and

- Plotting the frequency curve and the confident limits.

An LP-III distribution was selected based on the guidance in Kuczera and Franks (2005) and Bulletin 17-B (U.S. Interagency Advisory Committee on Water Data, 1982). In addition, a Bayesian approach was used to estimate the parameters in the LP-III distribution and the uncertainty in these parameters.

Selection of flood series: As recommended by (Kuczera and Franks, 2016) for a gauge with more than 10 years of record, an AMS was used to determine the flood series. The selected period for analysis discovered the period from 1980 to 2010.

Detection of outliers for the LP-III distribution was undertaken using the methodology described by Interagency Advisory Committee on Water Data, (1982). The adopted high and low threshold for the gauge are shown in Table 1. Using the data in this table, peak flows of $326 \mathrm{~m}^{3} / \mathrm{s}$ (1978), $250 \mathrm{~m}^{3} / \mathrm{s}$ (1989), and $275 \mathrm{~m}^{3} / \mathrm{s}$ (2006) at the An Khe gauge were treated as censored data.

Frequency curves: Flood quantiles were estimated using the FLIKE software (Kuczera and Franks, 2016) with an LP-III distribution and Bayesian parameter estimation. No prior information was used in the analysis.

In general, use of the LP-III distribution produced consistent results with, in the majority of cases, the observed data within the confidence limits as shown in Figure 2. The most probable values of LP-III distribution parameters (i.e. the location, scale, and shape parameters) and the standard deviation of these parameters are presented in Table 2. The most probable value of the location parameter (mean of $\log$ flow) is 7.0422, while an acceptable range is $7.0422 \pm 0.09018$; this acceptable range is the most probable value \pm one standard deviation. In a similar manner, the most probable value of the scale parameter $\left(\log _{\mathrm{e}}\right.$ [standard deviation $\left(\log _{\mathrm{e}}\right.$ flow)] $)$ is -0.74320 and the acceptable range is $0.74320 \pm 0.15064$. Finally, the most probable value of the shape parameter (skewness) is -0.56875 and the acceptable range is $-0.56875 \pm 0.09018$. Correlations between the values of these parameters are shown in Table 2 also.

\section{MODEL IMPLEMENTATION}

Flows in the river basin were simulated using HEC-HMS which is described by US Army Corps of Engineers (2010) as being a physically based, semi-distributed parameter model. Application of this software used gridded rainfall with a 2000-m resolution while the SCS curve number method was used as the loss model. For the rainfall to runoff transform, a kinematic wave approach was applied with flood wave translation along channel reaches simulated using a Muskingum-Cunge technique. 


\subsection{Rainfall Model and Method of Fragments for Rainfall Disaggregation}

Gridded rainfall data are necessary for implementation of the model. Therefore, an Inverse Distance Weight method using rainfall data at nine stations across the catchment was used to generate the gridded pattern of rainfall over the catchment.

However, as previously noted, there were only four continuous rain gauges across the catchment; this is insufficient to reliably develop the rainfall grids. To generate additional data, the Method of Fragments was used to predict sub-daily data (1-hour increments were used in this study) at the daily rainfall gauges. More details of this approach are presented in Ball and $\mathrm{Cu}$ (2014).

\subsection{Catchment Stream Network and Preliminary Subcatchment Parameters}

Application of a distributed modelling system requires subdivision of a catchment into a number of subcatchments. For this study, the catchment was divided into 16 subcatchments as shown in (Figure 3) based on a Digital Elevation Model (DEM) with a horizontal resolution of 90m. An additional assumption was that each subcatchment should be small so that application of the kinematic wave model was feasible; a small catchment according to Vietnamese practice is less than $100 \mathrm{~km}^{2}$. At the same time, there is a need to ensure that the number of parameters to be determined during calibration of the model is not excessive. Shown in Table 3 are the primary calibration parameters for each subcatchment. As shown in that table, each subcatchment requires 10 parameters to be estimated.

Initial model parameter values were estimated using various sources such as land use and land cover maps, the DEM, and soil maps. All parameter maps had a horizontal resolution of $2000 \mathrm{~m}$, which was consistent with the rainfall grid data. Once the value of parameters had been estimated for individual grids, the average value of each parameter for each sub-catchment was determined.

\subsection{Model Operation}

The model was operated using an hourly step to predict continuous flow records for the period 19802011. These generated flow sequences were suitable for conducting an analysis using the FFA method for estimation of the design flood.

\subsection{Model Calibration}

Model calibration commonly is defined as the process for determination of parameter values. Both manual and computerized techniques have been used for undertaking this process (see, for example, Bevan and Binley, 1992, Kuczera and Parent 1998; Choi and Ball, 2002). The generic process is one where alternative sets of parameter values are tested against recorded data to enable determining the suitability of the parameter values. This test against recorded data requires a metric for comparative purposes. 
Calibration was conducted using a global search method, which based on 600 parameter sets randomly selected within an acceptable range of model parameter values. The fitness measure for assessing the calibration achieved was selected as a time series fit or a hydrograph fit using data from the An Khe gauge.

\subsection{AMS fitting method}

The measure of fit used in AMS fitting was based on the parameters of the flood model which are the three parameters for the flood probability model. As discussed above, the recorded flood probability model parameters and their confidence limits were estimated during application of the FFA method on the reported data. The model calibration, therefore, was searching for scenarios which produced LP-III parameters that fitted within the acceptable range of the parameters ascertained from the recorded data.

At An Khe gauge, the 20 best scenarios within the acceptable ranges were selected. Shown in Table 4 are the LP-III parameters from these parameter sets while shown in Figure 4 are the predicted AMSs plotted on the flood frequency diagram (Figure 5).

\subsection{Hydrograph fitting method}

The hydrograph fitting considered herein used the NSE as the objective function. The events selected for assessment of model performance were the same events used in developing the AMS from the recorded data. As a result, 28 events were extracted and used to perform the model calibration. A NSE was calculated for each event and then an average value for all events was determined for each parameter set.

Similar to assessment of the AMS fitting approach, the 20 best parameter sets were selected. The average NSE for these parameter sets varied from 0.47 to 0.52 . However, when individual events are considered, the NSE was usually higher; as shown in Table 5, the NSE was regularly above 0.9 for individual events.

Shown in Figure 6 is a comparison of the simulated and recorded hydrographs for these parameter sets. Comparisons of individual hydrographs are shown in Figure 7 to 13.

For the 20 selected sets of parameter values, AMSs were extracted to enable estimation of design flood quantiles by an FFA method. The LPIII parameters of simulated AMSs (location, scale, shape parameters) are shown in Table 6. It can be seen that the scale and shape parameters of the simulated AMSs were within the uncertainty of the observed values. However, the location parameter was underestimated. This resulted in underestimation of the design flood quantiles. 
The derived AMSs can be plotted on the flood frequency diagram derived from the historical data. As shown in Figure 14, the underestimation of the location parameter would result in a systematic underestimation of the design flood quantiles.

\subsection{Results}

For the 20 best sets of parameter values derived using either of the two measures of fitness, the parameter values for the resultant flood probability model were derived. These values are shown in Figures 15 to 17 together with the threshold values derived from analysis of the historical data.

As shown in Figure 15, the location parameter derived from the hydrograph fit measure was underestimated consistently. On the other hand, the location parameter derived from the AMS fit measure consistently was within the threshold bounds. The shape and scale values developed from analysis of the 20 best sets of parameter values were found to be within the threshold bounds and hence the values were considered acceptable.

\section{CONCLUSION}

The purpose of design flood estimation is the prediction of design flood quantiles. Two alternative measures of fit were considered for calibration of the parameters of a continuous catchment modelling system. Validation of the accepted parameter values was undertaken by using the predicted flows to estimate the design flood quantiles for both measures of fit. It was found that the AMS fitting was superior to the hydrograph fitting. In general, the hydrograph fitting method resulted in an underestimation of the design quantiles based on observed data primarily due to underestimation of the location parameter in the flood probability model.

\section{ACKNOWLEDGMENTS}

Support for the first author was provided by a VIED - UTS scholarship. The support of both the Australian and Vietnamese partners in this scholarship scheme is gratefully acknowledged.

\section{References}

Ball, J. E. 2013. Estimation of design floods using continuous simulation. Floodplain Management Association National Conference, Tweed Heads, NSW, Australia.

Ball, J.E. \& Cu, T. P. 2014. Daily Rainfall Disaggregation for a Monsoon Catchment in Vietnam. Hydrology \& Water Resources Symposium. Perth: Engineers Australia, ISBN 9781634399357

Bevan, K. and Binley, A., 1992. The future of distributed models: model calibration and uncertainty prediction. Hydrological Processes, 6, 279-298.

Calver, A. \& Lamb, R. 1995. Flood frequency estimation using continuous rainfall-runoff modelling. Physics and Chemistry of the Earth, 20, 479-483.

Cameron, D., et al., 1999. Flood frequency estimation by continuous simulation (with likelihood based uncertainty estimation). Hydrology and Earth System Sciences, 4, 23 -34. 
Choi, K. S., and Ball, J.E., 2002, Parameter estimation for urban runoff modelling, Urban Water, 4, $31-41$

Cohn, T. A., et. al., 2013. A generalized Grubbs-Beck test statistic for detecting multiple potentially influential low outliers in flood series, Water Resources Research, 49, 5047-5058.

Criss, R. E. \& Winston, W. E. 2008. Do Nash values have value? Discussion and alternate proposals. Hydrological Processes, 22, 2723-2725.

Das, T., et. al., 2008. Comparison of conceptual model performance using different representations of spatial variability. Journal of Hydrology, 356, 106-118.

Garrick, M., Cunnane, C. \& Nash, J. E. 1978. A criterion of efficiency for rainfall-runoff model. Journal of Hydrology, 36, 375-381.

Grubbs, F. E., Beck, G. 1972. Extension of sample sizes and percentage points for significance tests of outlying observations, Technometrics 4 (14), pp. 847-853.

Gupta, H. V., et. al., 2009. Decomposition of the mean squared error and NSE performance criteria: Implications for improving hydrological modeling. Journal of Hydrology, 377, 80-91.

Krause, P., Boyle, D. P. \& Base, F. 2005. Comparison of different efficiency criteria for hydrological model assessment. Advances in Geosciences, 5, 89-97.

Kuczera, G. and Parent, E., 1998. Monte Carlo assessment of parameter uncertainty in conceptual catchment models: the metropolis algorithm. Journal of Hydrology, 211, 69-85.

Kuczera, G. and Franks, S., 2016. At-site flood frequency analysis. In: J. Ball, M. Babister, R. Nathan, W. Weeks, E. Weinmann, M. Retallick and I. Testoni, eds. Australian rainfall and runoff: a guide to flood estimation. Commonwealth of Australia, Chap. 2, Book 3. Available from: http://arr.ga.gov.au/.

Lee, P. 1989. Bayesian Statistics: An Introduction. Charles Griffin. New York - Toronto.

Legates, D.R. and Mccabe, G.J.,1999. Evaluating the use of 'goodness-of-fit' measures in hydrologic and hydroclimatic model validation. Water Resources Research, 35, 233-241.

McMillan, H. \& Clark, M. 2009. Rainfall-runoff model calibration using informal likelihood measures within a Markov chain Monte Carlo sampling scheme. Water Resources Research, 45, W04418.

Podger, G. 2004. Rainfall Runoff Library User Manual. CRC for Catchment Hydrology.

Refsgaard, J. C. \& Knudsen, J. 1996. Operational Validation and Intercomparison of Different Types of Hydrological Models. Water Resources Research, 32, 2189-2202.

Seibert, J. 2001. On the need for benchmarks in hydrological modelling. Hydrological Processes, 15, 1063-1064.

Smithers, J. C. 2012. Methods for design flood estimation in South Africa. Water SA, 38, 633-646.

US Army Corps of Engineers, 2010. Hydrologic modeling system HEC - HMS, user's manual. Davis, CA: Hydrologic Engineering Center.

U.S. Interagency Advisory Committee on Water Data 1982. Guidelines for determining flood flow frequency, Bulletin 17-B of the Hydrology Subcommittee: Reston, Virginia, U.S. Geological Survey, Office of Water Data Coordination.

US Army Corps of Engineers 2010. Hydrologic Modeling System HEC - HMS, User's Manual. Davis, CA.: Hydrologic Engineering Center.

VKT KTTV\&MT, 2010. Đánh giá tác động của biến đổi khí hậu lên tài nguyên nước và các biện pháp thích úng - Luu vực sông Ba. Hanoi: Trung tâm nghiên cứu thủy văn và môi trường, Viện khoa học Khí Tượng Thủy văn \& Môi trường.

Westerberg, I. K., Guerrero, J.L., Younger, P. M., Beven, K. J., Seibert, J., Halldin, S., Freer, J. E. \& Xu, C.Y. 2011. Calibration of hydrological models using flow-duration curves. Hydrology and Earth System Sciences, 15, 2205-2227. 


\section{List of tables}

Table 1: High outlier and low outlier for annual maximum series ....................................... 31

Table 2: LP-III parameters for flood frequency at An Khe by Importance Sampling method 32

Table 3: Model parameters and their available ranges .......................................................... 33

Table 4: Parameters of LP-III distribution of simulated flow by hydrograph fitting and AMS

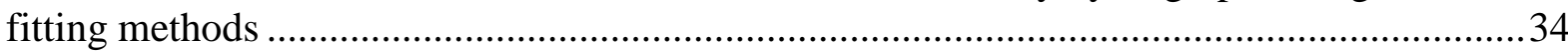

Table 5: NSE at some events for the best 20 parameter sets ................................................ 35

Table 6: Parameters of LP-III distribution of simulated flow by hydrograph fitting and AMS

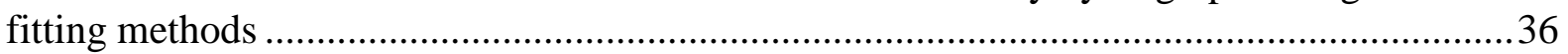


Figure 1: Distribution of meteorological stations across Ba basin. .................................................... 14

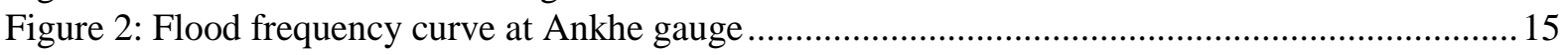

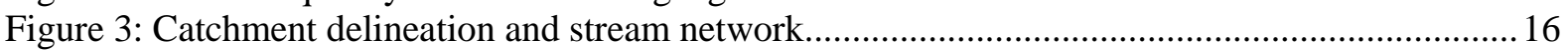

Figure 4: Graph A - Frequency analysis of AMS at An Khe gauge calibrated by AMS method ......... 17

Figure 5: Sorted simulated and observed AMS at An Khe gauge .................................................... 18

Figure 6: Observed and simulated hydrographs of all selected events at An Khe gauge ..................... 19

Figure 7: Hydrographs of recorded flow and simulated flow at An Khe gauge 1985 ..........................20

Figure 8: Hydrographs of recorded flow and simulated flow at An Khe gauge 1986 ........................21

Figure 9: Hydrographs of recorded flow and simulated flow at An Khe gauge 1987 .........................22

Figure 10: Hydrographs of recorded flow and simulated flow at An Khe gauge 1988 ........................23

Figure 11: Hydrographs of recorded flow and simulated flow at An Khe gauge 2001 ........................24

Figure 12: Hydrographs of recorded flow and simulated flow at An Khe gauge 2009 ........................25

Figure 13: Hydrographs of recorded flow and simulated flow at An Khe gauge 2008 .......................26

Figure 14: Graph B - Frequency analysis of AMS at An Khe gauge calibrated by hydrograph fitting

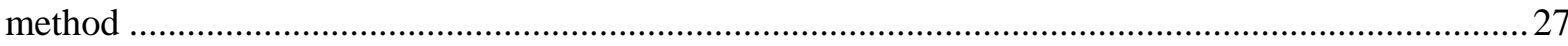

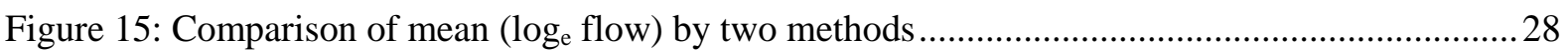

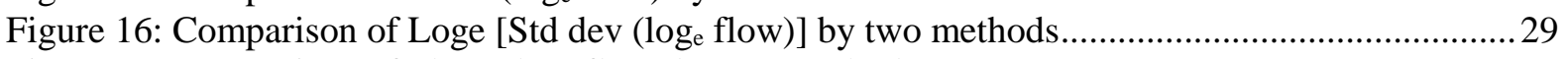

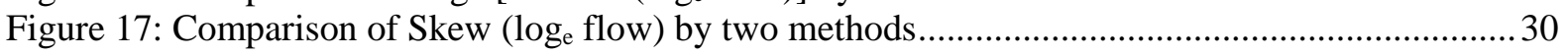




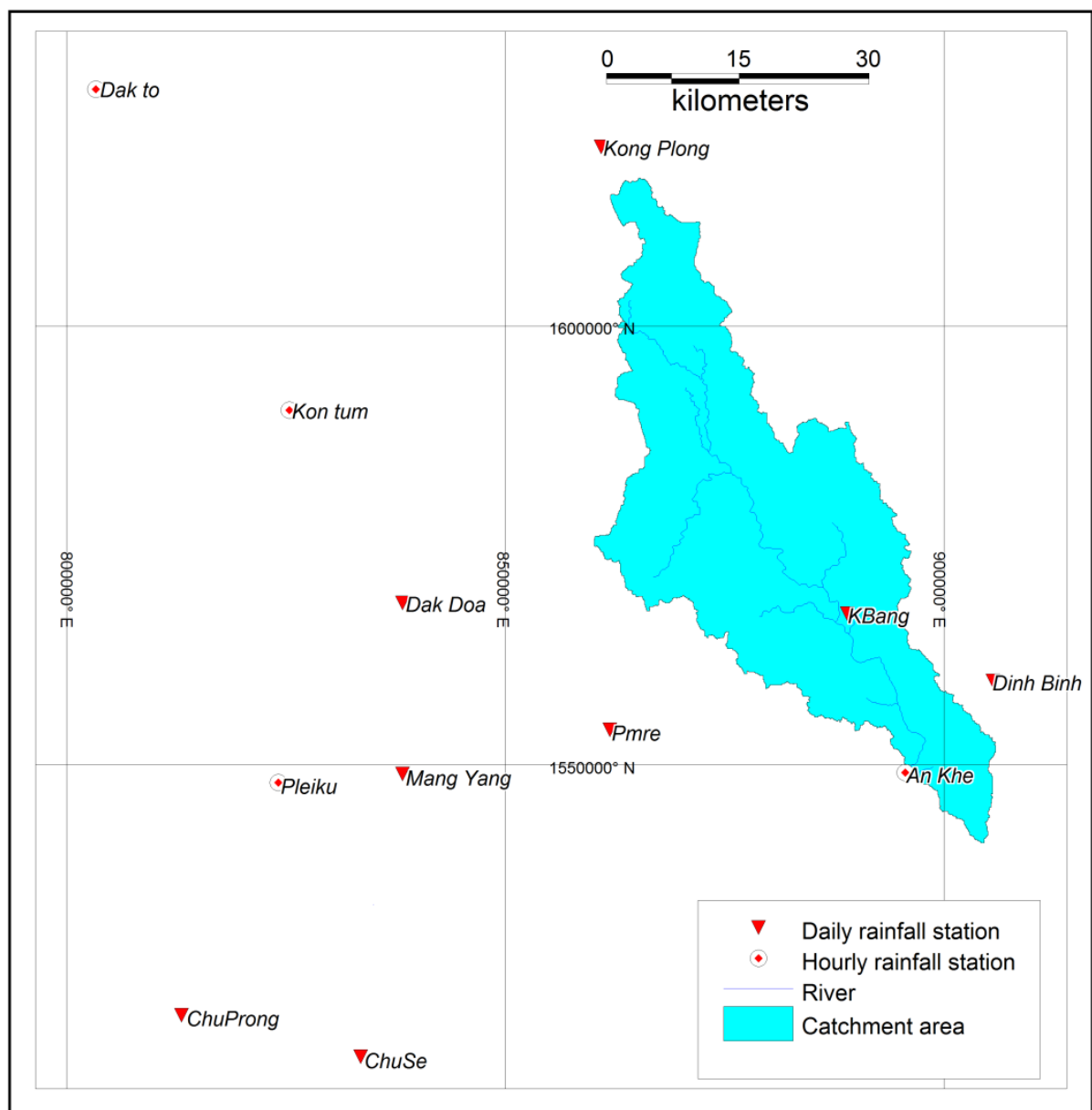

Figure 1: Distribution of meteorological stations across Ba basin. 


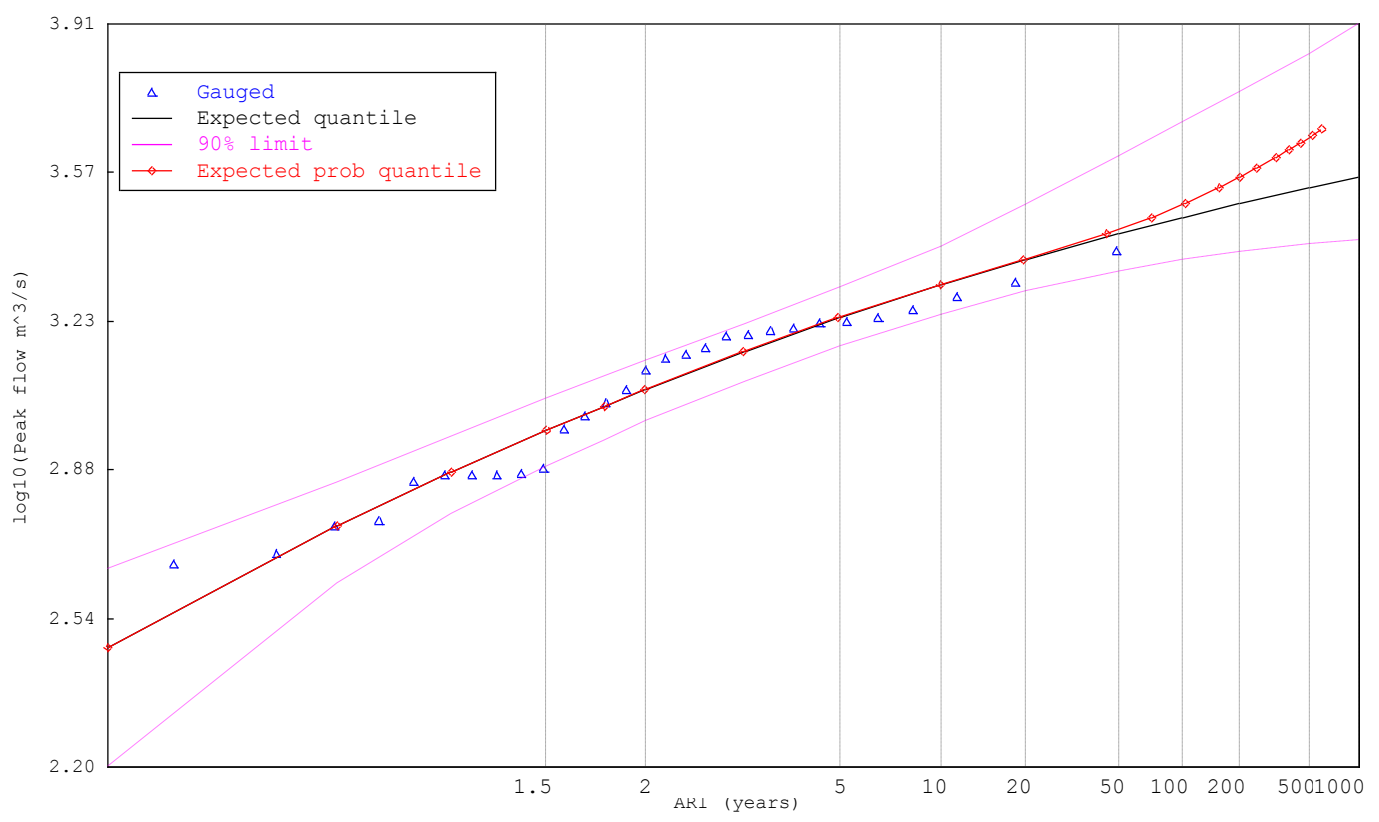

Figure 2: Flood frequency curve at Ankhe gauge 


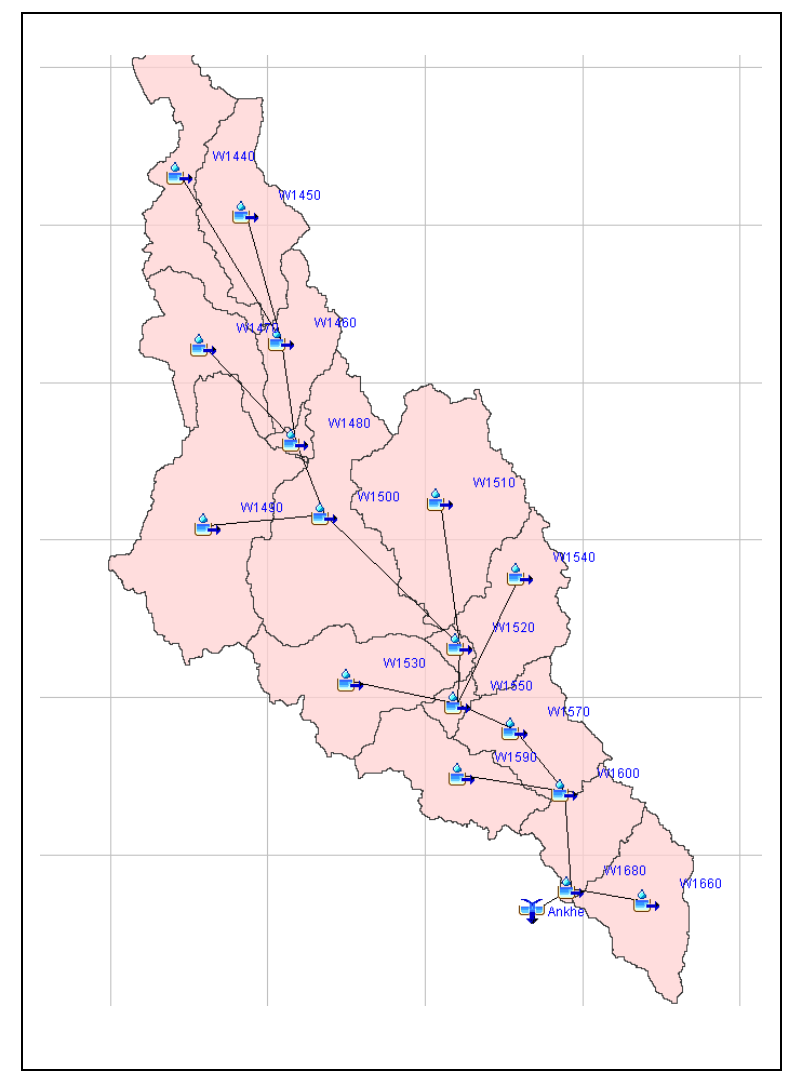

Figure 3: Catchment delineation and stream network 


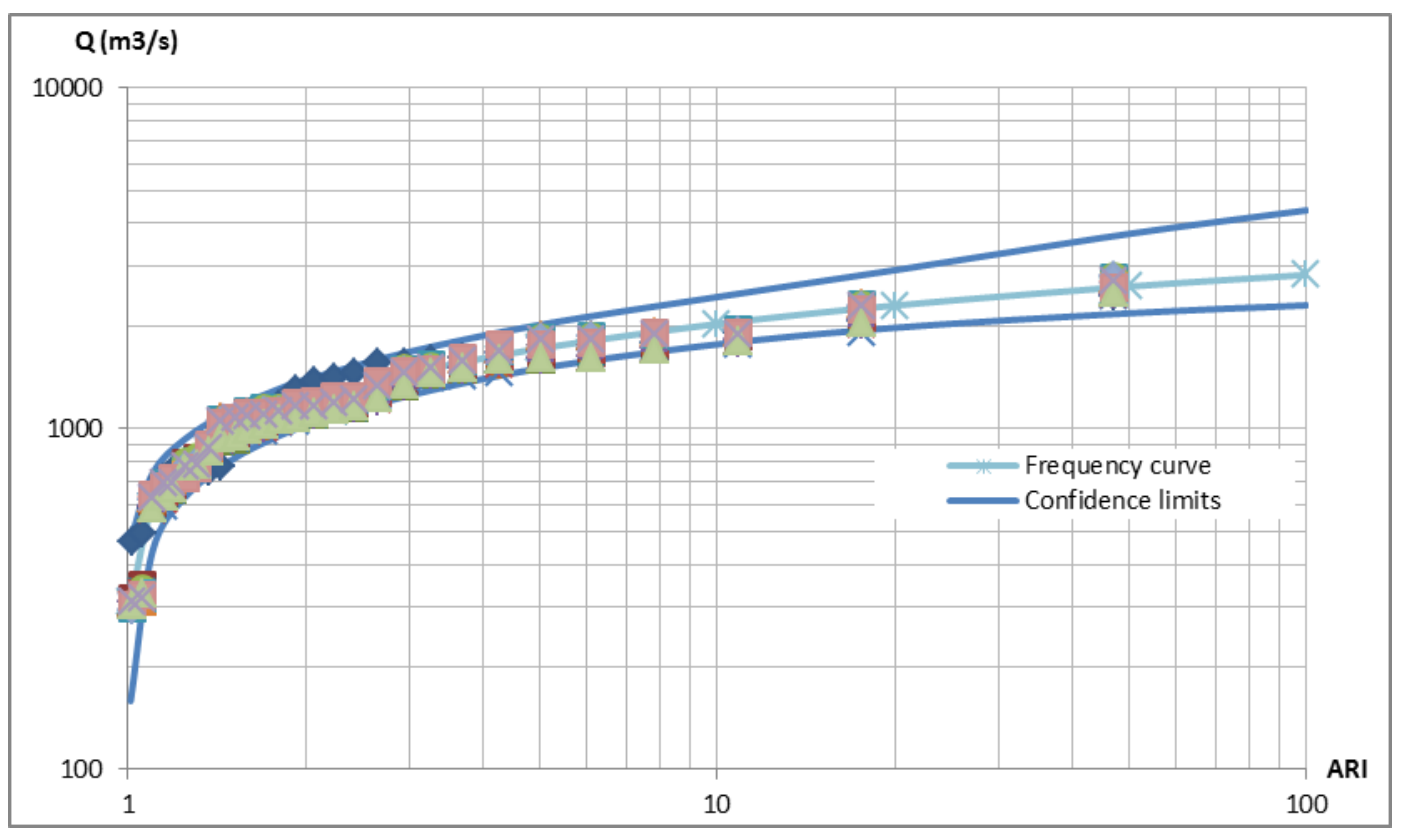

Figure 4: Graph A - Frequency analysis of AMS at An Khe gauge calibrated by AMS method 


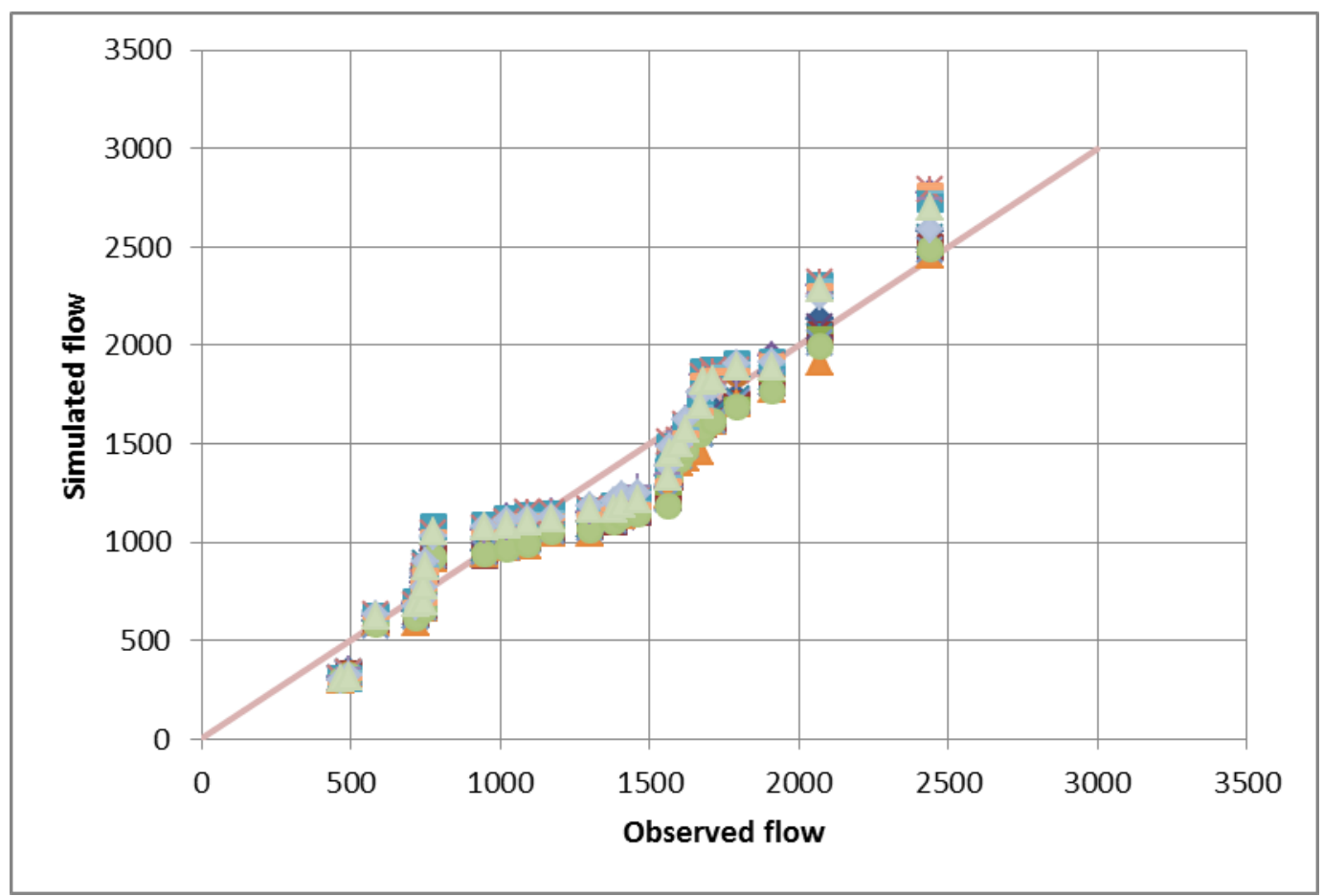

Figure 5: Sorted simulated and observed AMS at An Khe gauge 


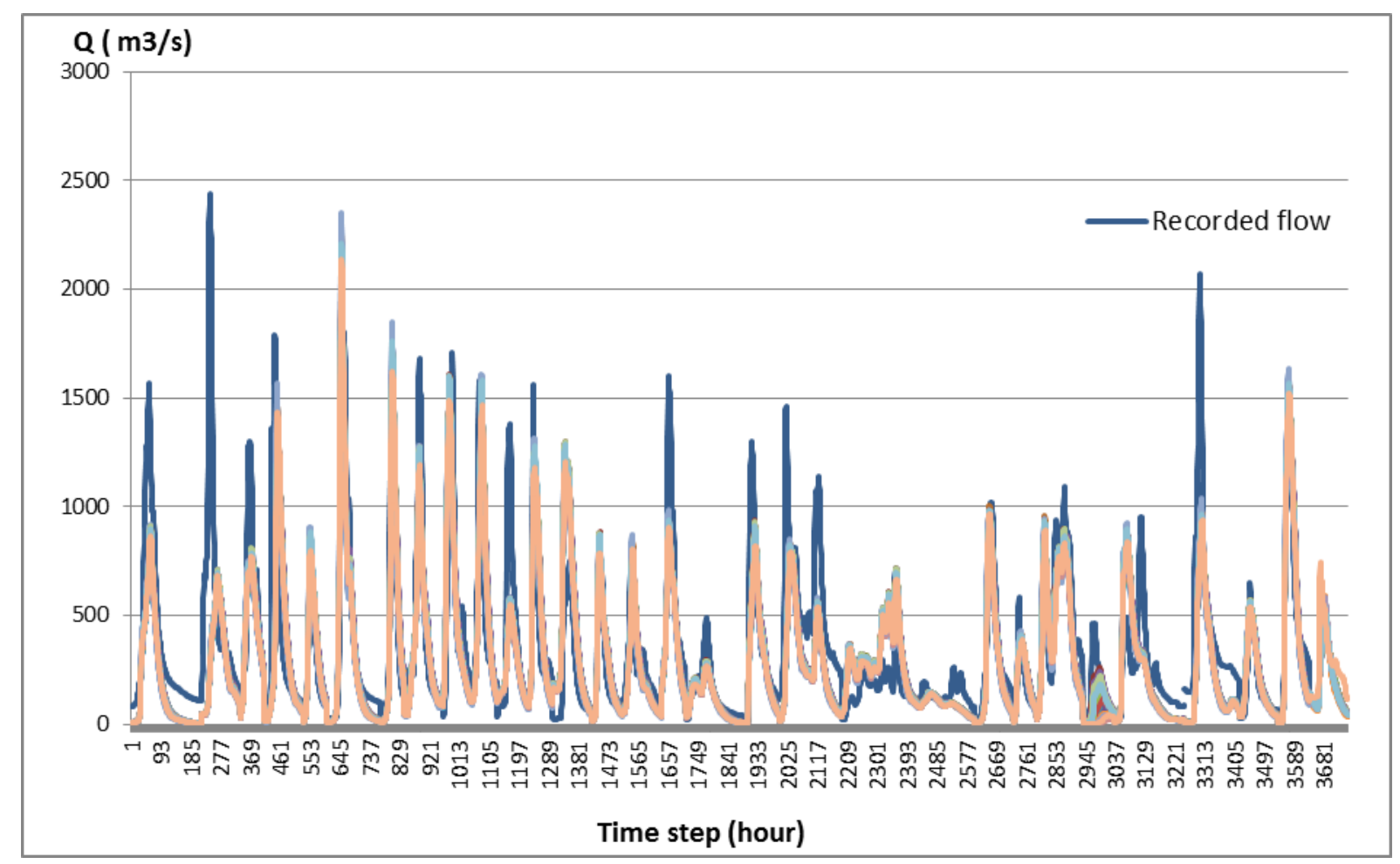

Figure 6: Observed and simulated hydrographs of all selected events at An Khe gauge 


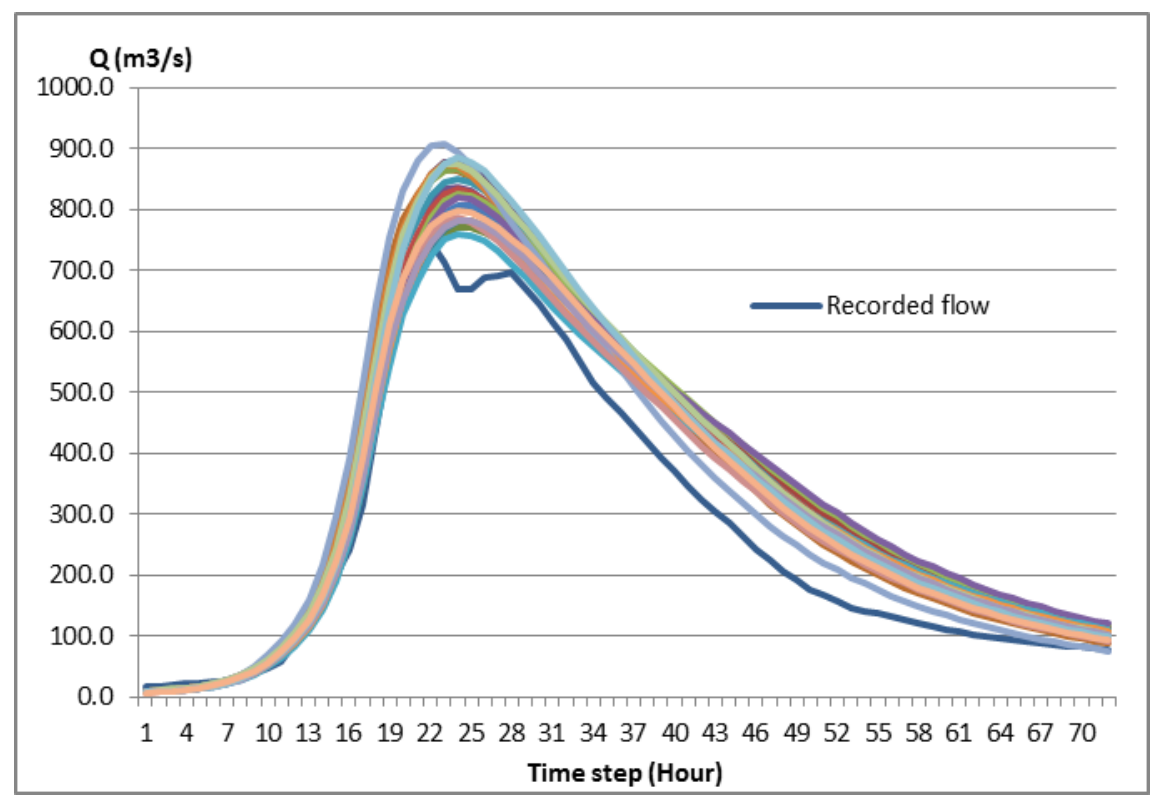

Figure 7: Hydrographs of recorded flow and simulated flow at An Khe gauge 1985 


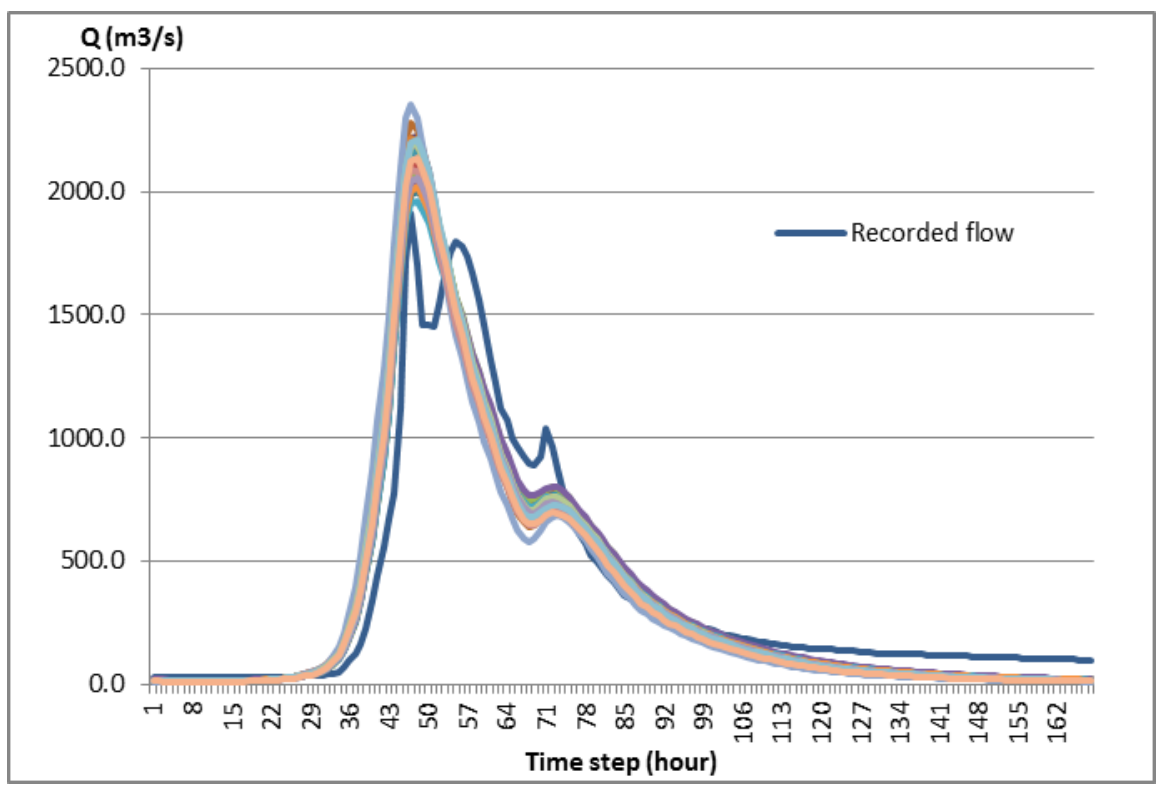

Figure 8: Hydrographs of recorded flow and simulated flow at An Khe gauge 1986 


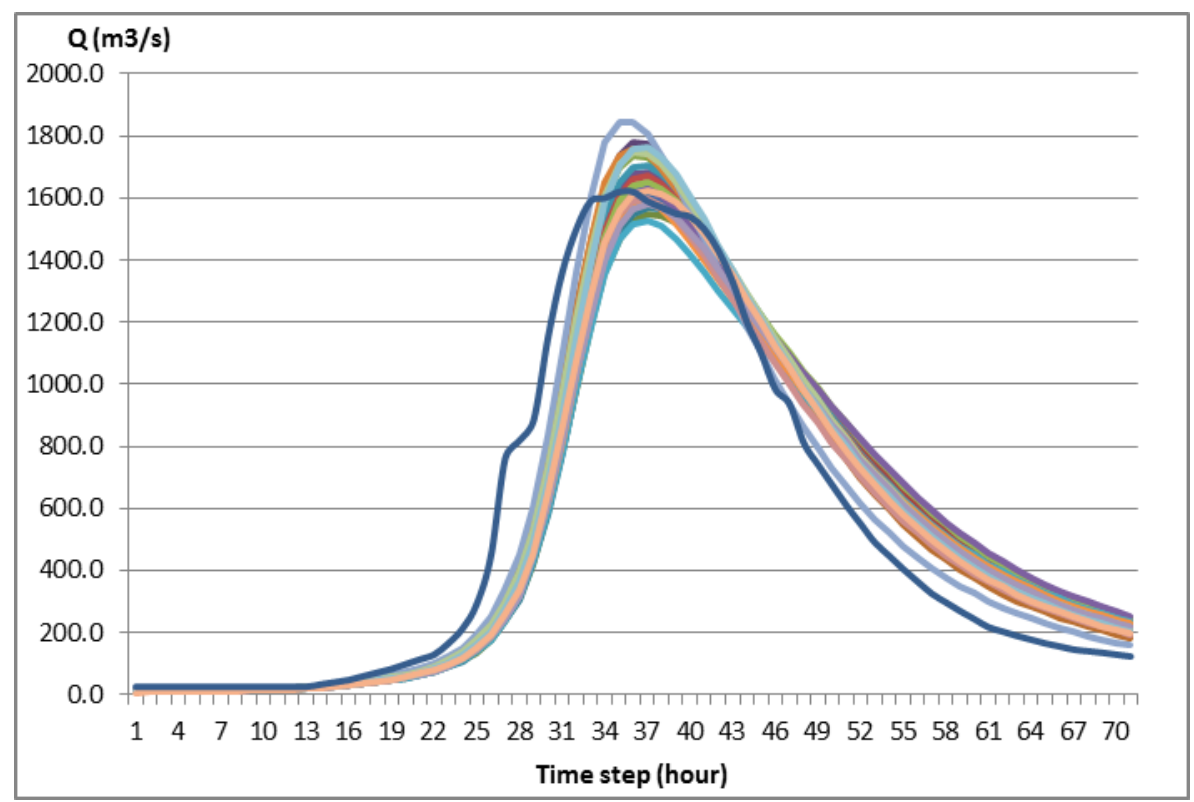

Figure 9: Hydrographs of recorded flow and simulated flow at An Khe gauge 1987 


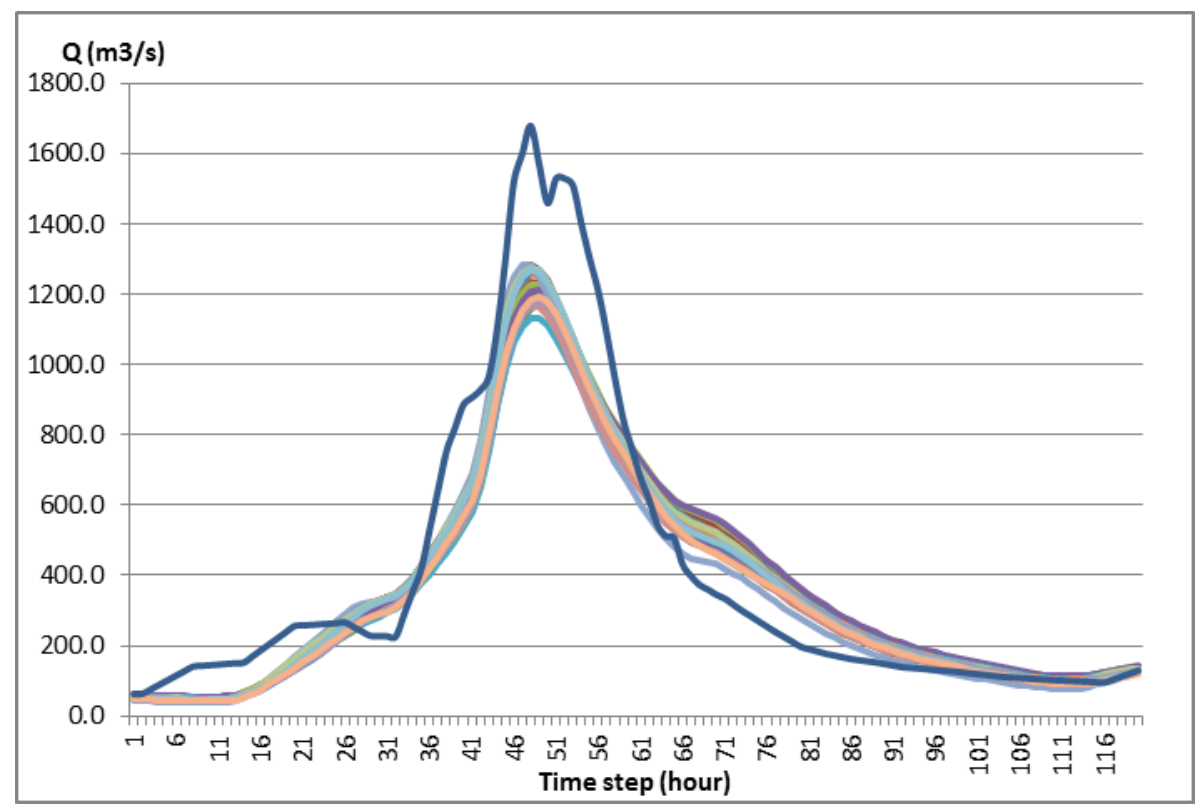

Figure 10: Hydrographs of recorded flow and simulated flow at An Khe gauge 1988 


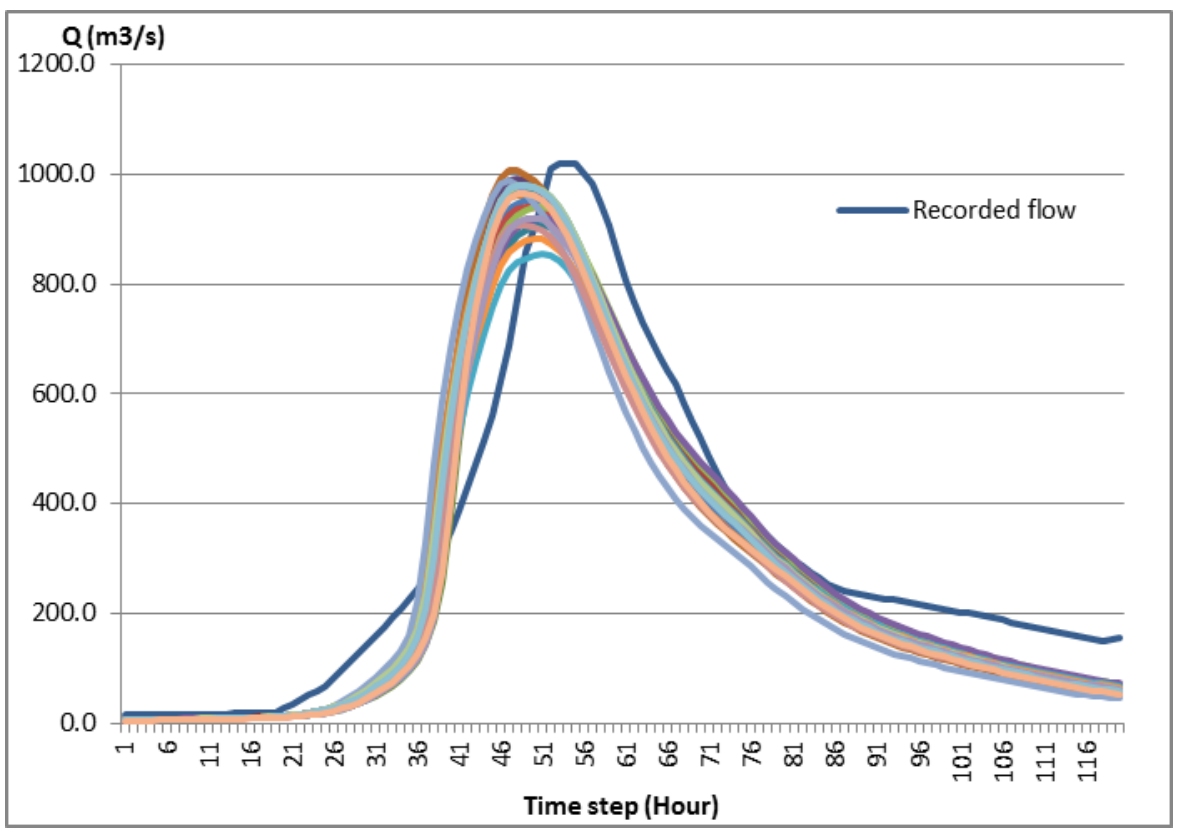

Figure 11: Hydrographs of recorded flow and simulated flow at An Khe gauge 2001 


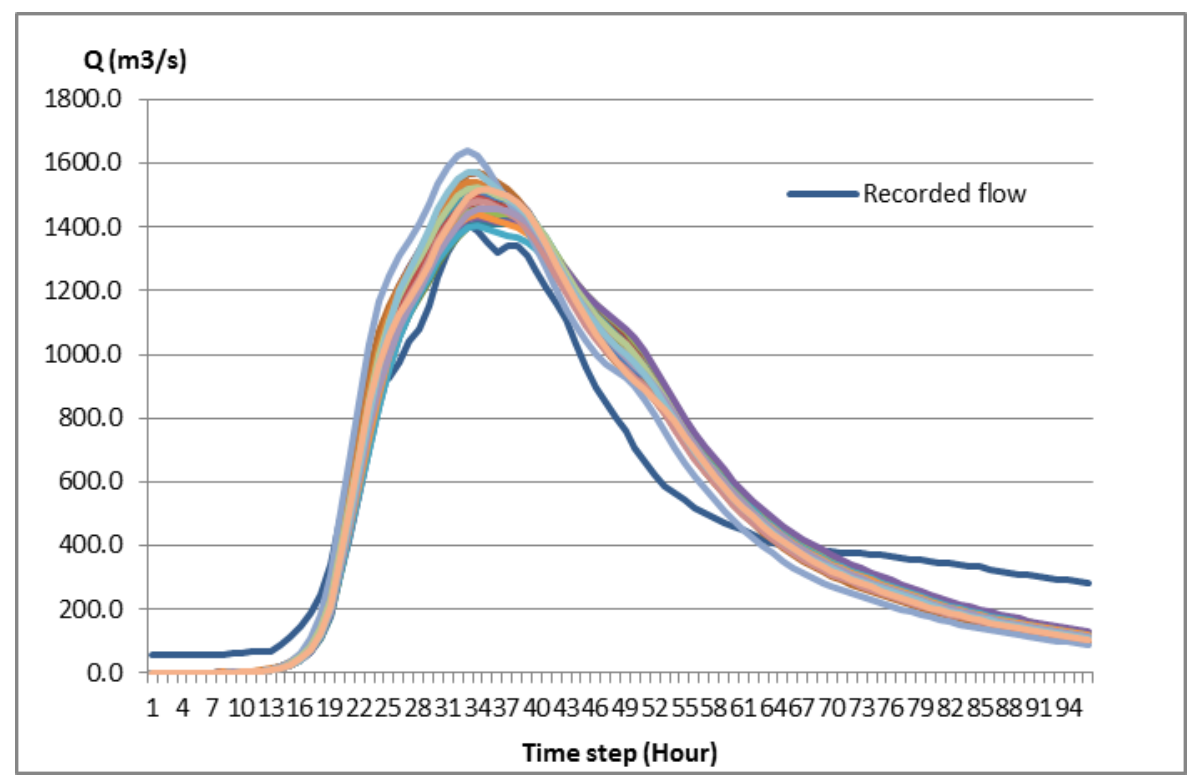

Figure 12: Hydrographs of recorded flow and simulated flow at An Khe gauge 2009 


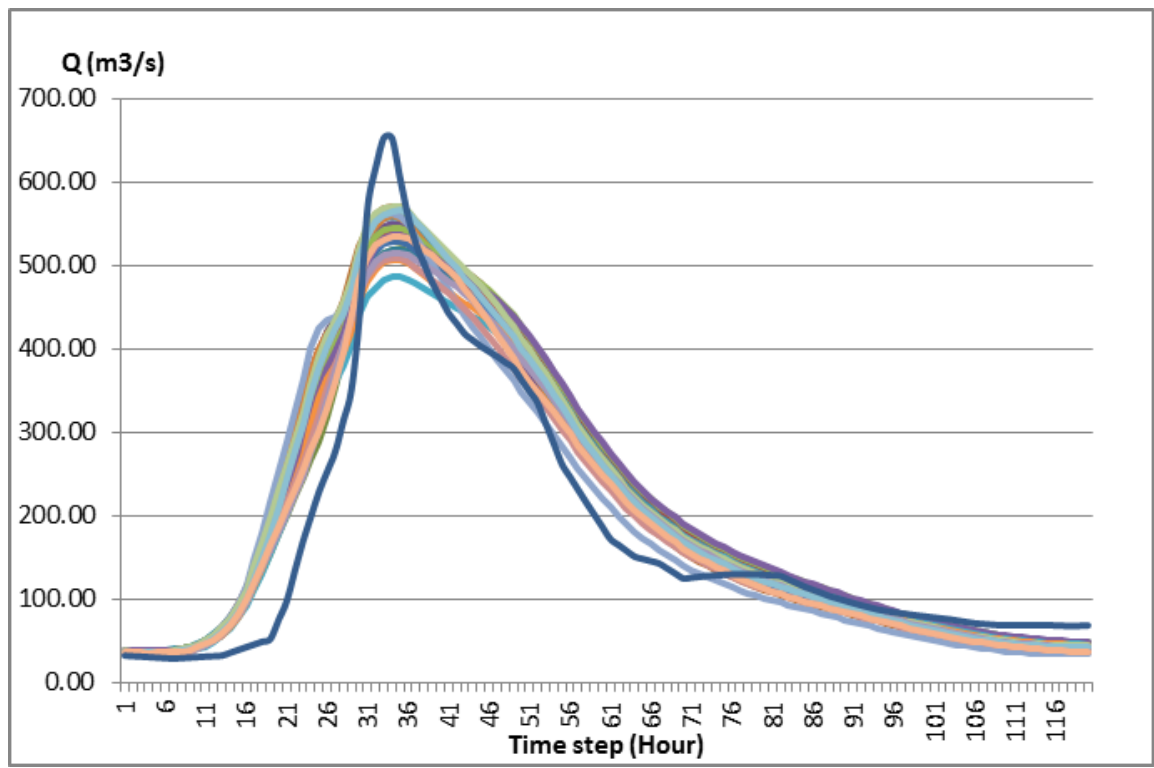

Figure 13: Hydrographs of recorded flow and simulated flow at An Khe gauge 2008 


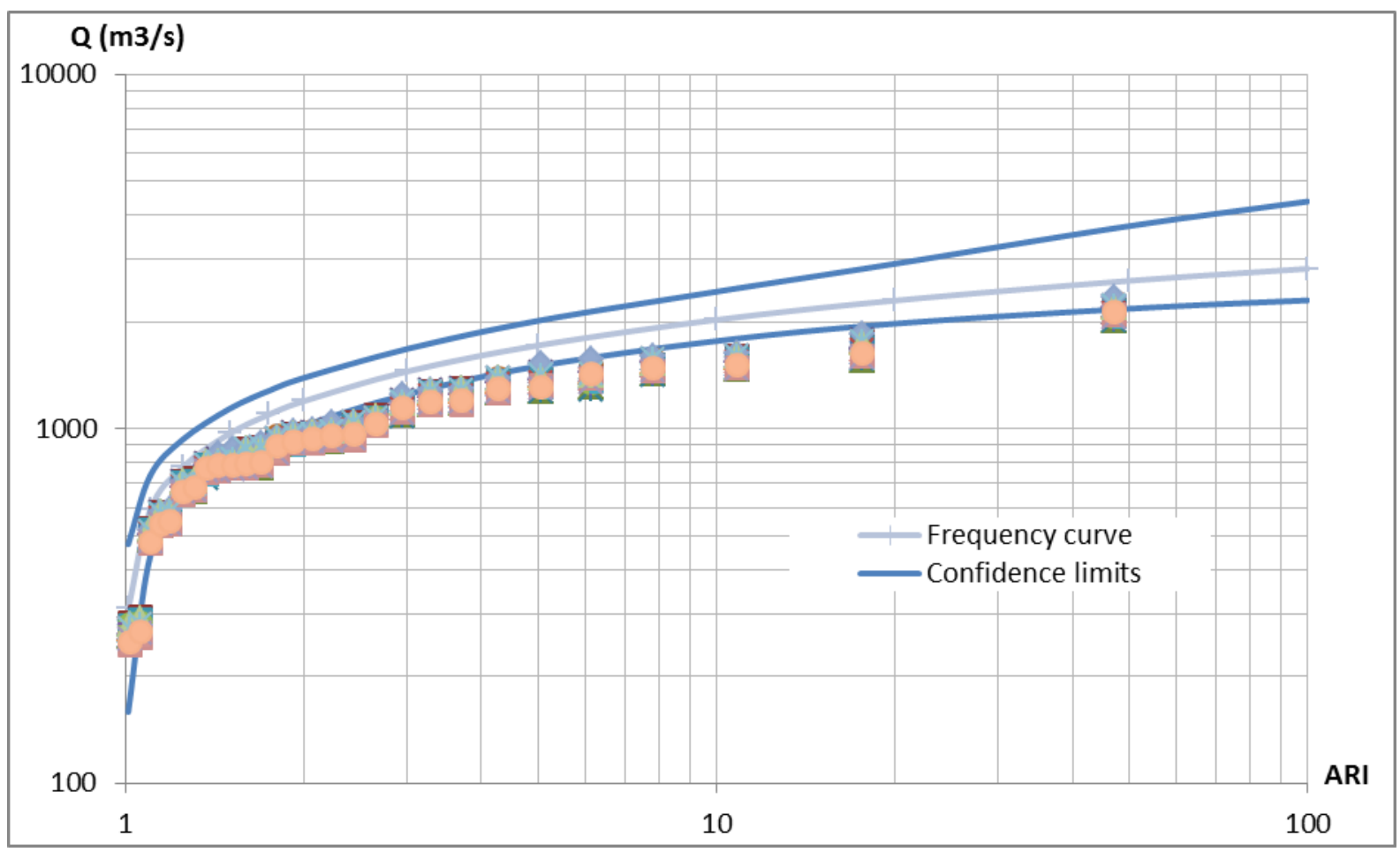

Figure 14: Graph B-Frequency analysis of AMS at An Khe gauge calibrated by hydrograph fitting method 


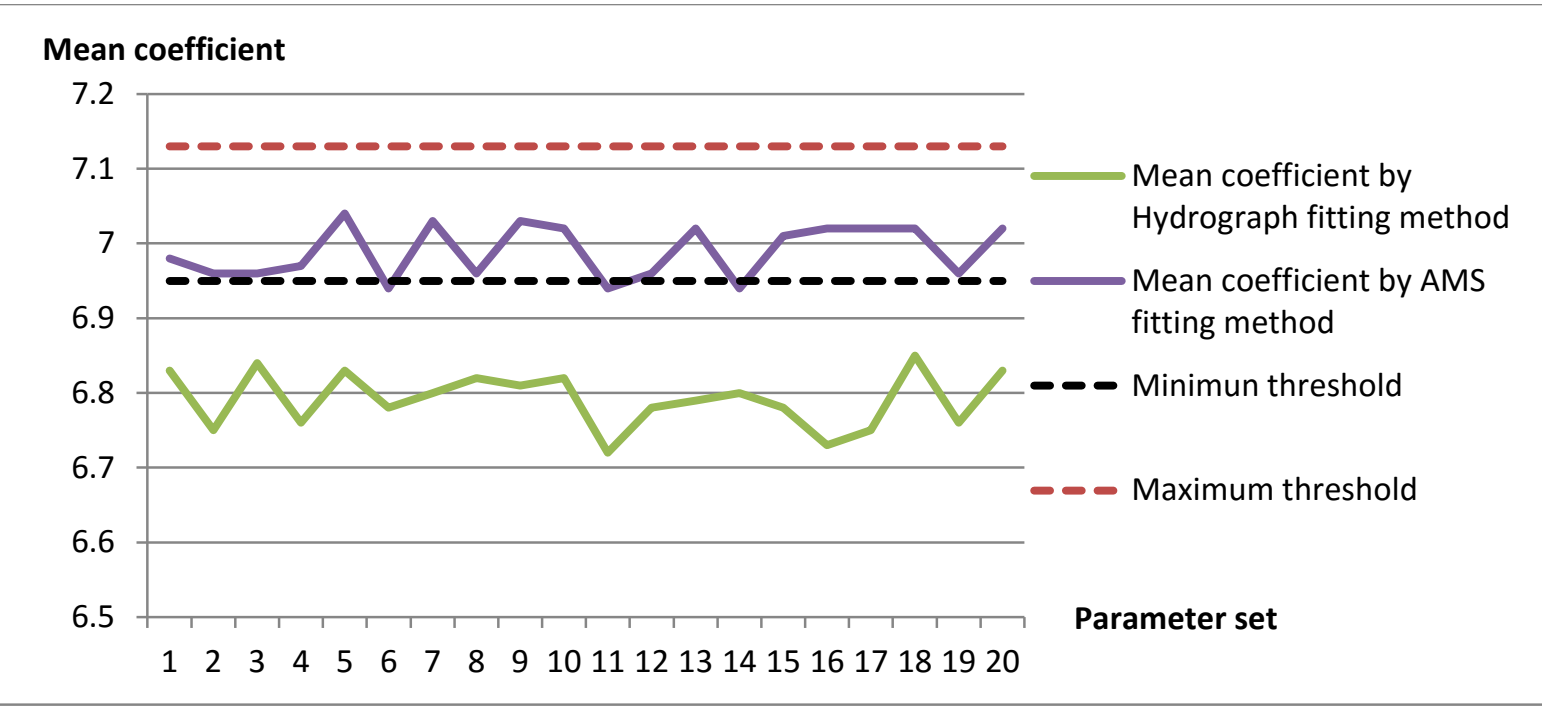

Figure 15: Comparison of mean ( $\log _{e}$ flow) by two methods 


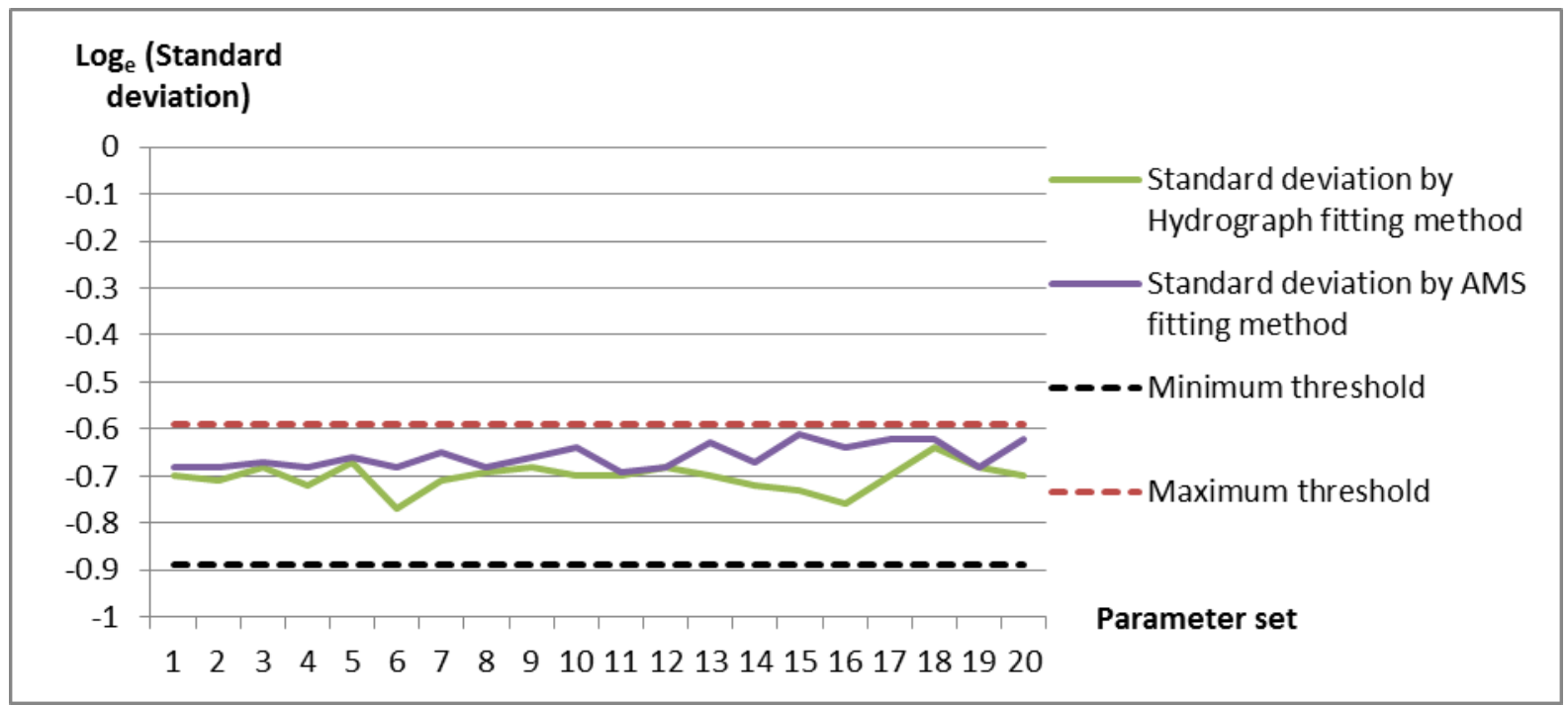

Figure 16: Comparison of $\log _{e}\left[\right.$ Std dev $\left(\log _{e}\right.$ flow)] by two methods 


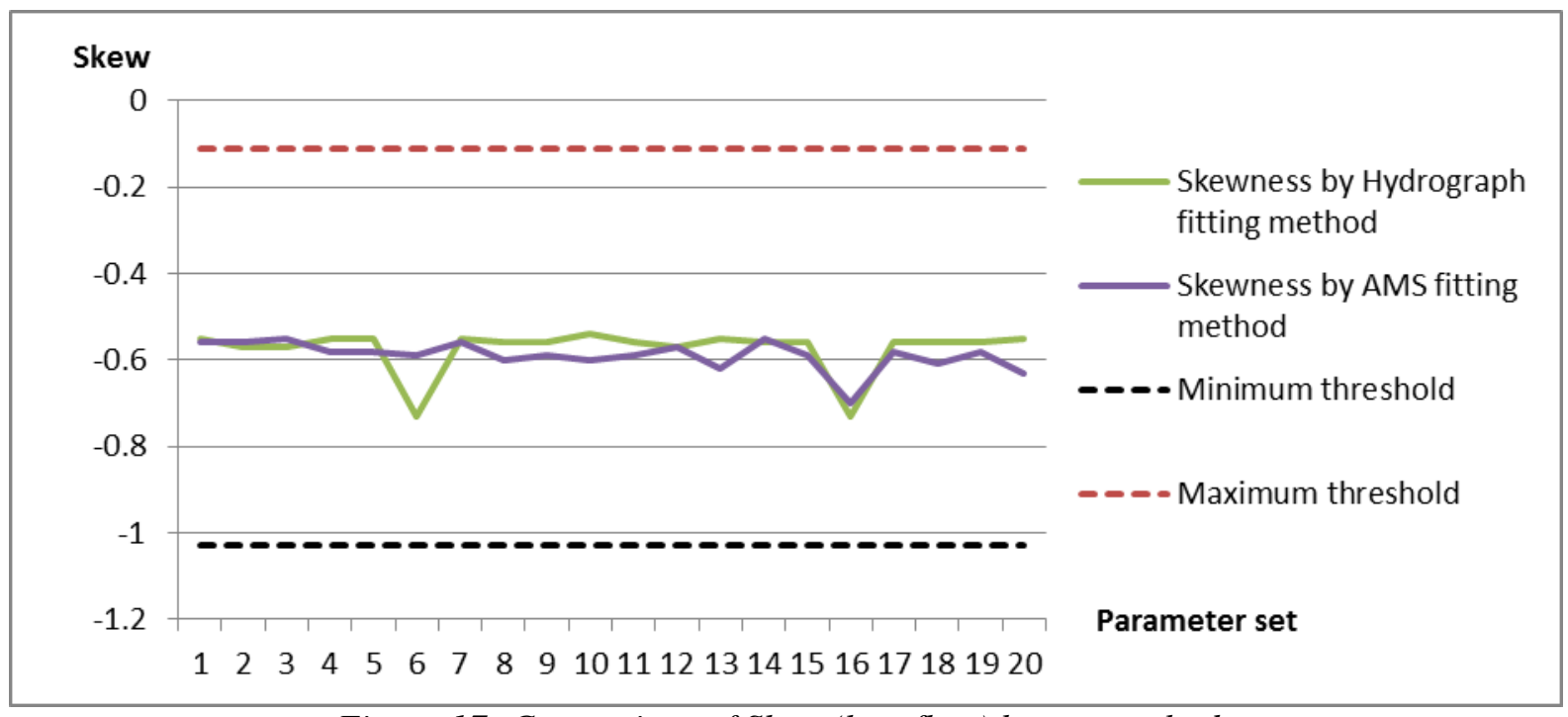

Figure 17: Comparison of Skew ( $\log _{e}$ flow) by two methods 
Table 1: High outlier and low outlier for annual maximum series

\begin{tabular}{|c|c|c|c|c|c|c|}
\hline \multirow{2}{*}{ Gauge } & \multirow{2}{*}{ Mean } & \multirow{2}{*}{$\boldsymbol{C}_{\boldsymbol{v}}$} & \multirow{2}{*}{$\boldsymbol{N}$} & \multirow{2}{*}{$\boldsymbol{K}_{\boldsymbol{N}}$} & \multicolumn{2}{|c|}{$\begin{array}{c}\text { Peak flow } \\
\text { Logarithms }\left(\mathrm{m}^{3} / \mathbf{s}\right)\end{array}$} \\
\cline { 5 - 7 } & & & & High threshold & Low threshold \\
\hline An Khe & 7.03 & 0.46 & 29 & 2.55 & $\begin{array}{c}8.2089 \\
(3673)\end{array}$ & $\begin{array}{c}5.8448 \\
(345)\end{array}$ \\
\hline
\end{tabular}


Table 2: LP-III parameters for flood frequency at An Khe by Importance Sampling method

\begin{tabular}{|c|l|l|l|l|l|l|}
\hline $\boldsymbol{N}$ & \multicolumn{1}{|c|}{ Parameters } & \multicolumn{1}{|c|}{$\begin{array}{c}\text { Most Probable } \\
\text { value }\end{array}$} & $\begin{array}{c}\text { Standard } \\
\text { deviation }\end{array}$ & \multicolumn{3}{|c|}{ Correlation } \\
\hline 1 & Mean $\left(\log _{\mathrm{e}}\right.$ flow $)$ & 7.0422 & 0.09018 & 1.000 & & \\
\hline 2 & Loge $\left[\right.$ Std dev $\left(\log _{\mathrm{e}}\right.$ flow $\left.)\right]$ & -0.74320 & 0.15064 & -0.350 & 1.000 & \\
\hline 3 & Skew $\left(\log _{\mathrm{e}}\right.$ flow $)$ & -0.56875 & 0.45883 & 0.042 & -0.230 & 1.000 \\
\hline
\end{tabular}


Table 3: Model parameters and their available ranges

\begin{tabular}{|c|c|c|}
\hline Models & Parameters & Range \\
\hline Loss models & Curve number & $20-90$ \\
\hline \multirow{3}{*}{$\begin{array}{c}\text { Kinematic wave } \\
\text { (Overland flow planes) }\end{array}$} & Typical length & $0.0001-1$ \\
\cline { 2 - 3 } & Representative slope & $0.35-0.8$ \\
\cline { 2 - 3 } & Overland-flow roughness coefficient & \\
\cline { 2 - 3 } & Area represented by plane & Rectangular \\
\hline \multirow{3}{*}{$\begin{array}{c}\text { Musking-Cunge routing } \\
\text { (The main channel) }\end{array}$} & Main channel length & $0.0001-1$ \\
\cline { 2 - 3 } & Description of main channel shape & \\
\cline { 2 - 3 } & Channel slope & $0.035-0.08$ \\
\cline { 2 - 3 } & Channel width & \\
\cline { 2 - 3 } & Representative Manning's roughness \\
& coefficient & \\
\hline
\end{tabular}


Table 4: Parameters of LP-III distribution of simulated flow by hydrograph fitting and AMS fitting methods

\begin{tabular}{|c|c|c|c|c|}
\hline$N$ & $\begin{array}{c}N- \\
\text { Parameter } \\
\text { set }\end{array}$ & $\begin{array}{c}\text { Mean } \\
\left(\log _{e}\right. \\
\text { flow) }\end{array}$ & $\begin{array}{c}\log _{e} \\
\text { [Std dev } \\
\text { (loge } \\
\text { flow)] }\end{array}$ & $\begin{array}{l}\text { Skew } \\
\left(\log _{e}\right. \\
\text { flow })\end{array}$ \\
\hline 1 & 1038 & 6.98 & -0.68 & -0.56 \\
\hline 2 & 1059 & 6.96 & -0.68 & -0.56 \\
\hline 3 & 1117 & 6.96 & -0.67 & -0.55 \\
\hline 4 & 1126 & 6.97 & -0.68 & -0.58 \\
\hline 5 & 1160 & 7.04 & -0.66 & -0.58 \\
\hline 6 & 1172 & 6.94 & -0.68 & -0.59 \\
\hline 7 & 1177 & 7.03 & -0.65 & -0.56 \\
\hline 8 & 1223 & 6.96 & -0.68 & -0.60 \\
\hline 9 & 1278 & 7.03 & -0.66 & -0.59 \\
\hline 10 & 1286 & 7.02 & -0.64 & -0.60 \\
\hline 11 & 1303 & 6.94 & -0.69 & -0.59 \\
\hline 12 & 1334 & 6.96 & -0.68 & -0.57 \\
\hline 13 & 1336 & 7.02 & -0.63 & -0.62 \\
\hline 14 & 1350 & 6.94 & -0.67 & -0.55 \\
\hline 15 & 1357 & 7.01 & -0.61 & -0.59 \\
\hline 16 & 1437 & 7.02 & -0.64 & -0.70 \\
\hline 17 & 1457 & 7.02 & -0.62 & -0.58 \\
\hline 18 & 1462 & 7.02 & -0.62 & -0.61 \\
\hline 19 & 1474 & 6.96 & -0.68 & -0.58 \\
\hline 20 & 1499 & 7.02 & -0.62 & -0.63 \\
\hline
\end{tabular}


Table 5: NSE at some events for the best 20 parameter sets

\begin{tabular}{|c|c|c|c|c|c|c|c|c|c|c|c|c|}
\hline \multirow{2}{*}{$N$} & \multirow{2}{*}{$N$ - Parameter set } & \multicolumn{11}{|c|}{ Event (year) } \\
\hline & & 1985 & 1986 & 1987 & 1988 & 1992 & 1994 & 1997 & 2001 & 2003 & 2008 & 2009 \\
\hline 1 & 1001 & 0.82 & 0.96 & 0.91 & 0.89 & 0.72 & 0.75 & 0.77 & 0.86 & 0.76 & 0.83 & 0.87 \\
\hline 2 & 1022 & 0.88 & 0.93 & 0.86 & 0.84 & 0.69 & 0.82 & 0.71 & 0.89 & 0.67 & 0.90 & 0.89 \\
\hline 3 & 1039 & 0.84 & 0.96 & 0.92 & 0.89 & 0.75 & 0.77 & 0.75 & 0.82 & 0.73 & 0.86 & 0.87 \\
\hline 4 & 1089 & 0.86 & 0.92 & 0.86 & 0.84 & 0.68 & 0.80 & 0.73 & 0.90 & 0.71 & 0.89 & 0.88 \\
\hline 5 & 1168 & 0.86 & 0.97 & 0.94 & 0.89 & 0.78 & 0.80 & 0.72 & 0.79 & 0.69 & 0.87 & 0.88 \\
\hline 6 & 1173 & 0.86 & 0.93 & 0.88 & 0.85 & 0.69 & 0.79 & 0.75 & 0.90 & 0.74 & 0.87 & 0.88 \\
\hline 7 & 1276 & 0.84 & 0.94 & 0.89 & 0.87 & 0.70 & 0.77 & 0.76 & 0.89 & 0.74 & 0.86 & 0.87 \\
\hline 8 & 1360 & 0.85 & 0.96 & 0.92 & 0.89 & 0.75 & 0.77 & 0.75 & 0.84 & 0.73 & 0.86 & 0.88 \\
\hline 9 & 1378 & 0.88 & 0.96 & 0.92 & 0.88 & 0.75 & 0.81 & 0.72 & 0.83 & 0.69 & 0.89 & 0.88 \\
\hline 10 & 1379 & 0.84 & 0.95 & 0.91 & 0.88 & 0.71 & 0.77 & 0.76 & 0.86 & 0.74 & 0.86 & 0.87 \\
\hline 11 & 1386 & 0.86 & 0.96 & 0.93 & 0.88 & 0.77 & 0.79 & 0.74 & 0.82 & 0.73 & 0.86 & 0.88 \\
\hline 12 & 1387 & 0.89 & 0.94 & 0.89 & 0.86 & 0.71 & 0.82 & 0.71 & 0.86 & 0.66 & 0.90 & 0.89 \\
\hline 13 & 1405 & 0.86 & 0.95 & 0.90 & 0.87 & 0.72 & 0.79 & 0.75 & 0.87 & 0.73 & 0.87 & 0.88 \\
\hline 14 & 1418 & 0.83 & 0.94 & 0.88 & 0.86 & 0.68 & 0.77 & 0.77 & 0.90 & 0.75 & 0.85 & 0.87 \\
\hline 15 & 1452 & 0.83 & 0.93 & 0.86 & 0.85 & 0.67 & 0.76 & 0.76 & 0.91 & 0.75 & 0.86 & 0.87 \\
\hline 16 & 1468 & 0.91 & 0.92 & 0.87 & 0.82 & 0.72 & 0.83 & 0.69 & 0.89 & 0.70 & 0.90 & 0.90 \\
\hline 17 & 1470 & 0.90 & 0.93 & 0.88 & 0.84 & 0.72 & 0.82 & 0.71 & 0.88 & 0.71 & 0.90 & 0.89 \\
\hline 18 & 1507 & 0.86 & 0.97 & 0.96 & 0.89 & 0.83 & 0.81 & 0.69 & 0.72 & 0.69 & 0.85 & 0.85 \\
\hline 19 & 1511 & 0.93 & 0.94 & 0.91 & 0.85 & 0.77 & 0.85 & 0.67 & 0.84 & 0.65 & 0.91 & 0.90 \\
\hline 20 & 1539 & 0.82 & 0.96 & 0.91 & 0.89 & 0.73 & 0.75 & 0.77 & 0.85 & 0.74 & 0.84 & 0.87 \\
\hline
\end{tabular}


Table 6: Parameters of LP-III distribution of simulated flow by hydrograph fitting and AMS fitting methods

\begin{tabular}{|c|c|c|c|c|}
\hline$N$ & $\begin{array}{c}N \text { - Parameter } \\
\text { set }\end{array}$ & $\begin{array}{c}\text { Mean }\left(\log _{e}\right. \\
\text { flow) }\end{array}$ & $\begin{array}{c}\log _{e}[\text { Std } \\
\operatorname{dev}\left(\log _{e}\right. \\
\text { flow)] }\end{array}$ & $\begin{array}{c}\text { Skew (log } \\
\text { flow) }\end{array}$ \\
\hline 1 & 1001 & 6.83 & -0.70 & -0.55 \\
\hline 2 & 1022 & 6.75 & -0.71 & -0.57 \\
\hline 3 & 1039 & 6.84 & -0.68 & -0.57 \\
\hline 4 & 1089 & 6.76 & -0.72 & -0.55 \\
\hline 5 & 1168 & 6.83 & -0.67 & -0.55 \\
\hline 6 & 1173 & 6.78 & -0.77 & -0.73 \\
\hline 7 & 1276 & 6.80 & -0.71 & -0.55 \\
\hline 8 & 1360 & 6.82 & -0.69 & -0.56 \\
\hline 9 & 1378 & 6.81 & -0.68 & -0.56 \\
\hline 10 & 1379 & 6.82 & -0.70 & -0.54 \\
\hline 11 & 1386 & 6.72 & -0.70 & -0.56 \\
\hline 12 & 1387 & 6.78 & -0.68 & -0.57 \\
\hline 13 & 1405 & 6.79 & -0.70 & -0.55 \\
\hline 14 & 1418 & 6.80 & -0.72 & -0.56 \\
\hline 15 & 1452 & 6.78 & -0.73 & -0.56 \\
\hline 16 & 1468 & 6.73 & -0.76 & -0.73 \\
\hline 17 & 1470 & 6.75 & -0.70 & -0.56 \\
\hline 18 & 1507 & 6.85 & -0.64 & -0.56 \\
\hline 19 & 1511 & 6.76 & -0.68 & -0.56 \\
\hline 20 & 1539 & 6.83 & -0.70 & -0.55 \\
\hline
\end{tabular}

